\title{
Adoption of Human Resource Information Systems in Developing Countries: An Empirical Study
}

\author{
G. M. Azmal Ali Quaosar ${ }^{1,2}$ \\ ${ }^{1}$ Center for Modern Information Management, School of Management, Huazhong University of Science and \\ Technology, Wuhan, Hubei 430074, P. R. China \\ ${ }^{2}$ Department of Management Studies, Comilla University, Comilla-3506, Bangladesh \\ Correspondence: G. M. Azmal Ali Quaosar, Center for Modern Information Management, School of \\ Management, Huazhong University of Science and Technology, Wuhan, Hubei 430074, P. R. China; \\ Department of Management Studies, Comilla University, Comilla-3506, Bangladesh.
}

Received: January 29, 2018

Accepted: March 3, 2018

Online Published: March 12, 2018

doi:10.5539/ibr.v11n4p133

URL: https://doi.org/10.5539/ibr.v11n4p133

\begin{abstract}
There is an inadequate understanding of the successful use and effects of a human resource information system (HRIS) in a developing country context. Given this backdrop, this study plans to explore the determinants impact on HRIS adoption in a developing country. A research model was developed after studying the existing literature, and a questionnaire was developed accordingly to collect data through a purposive sampling method.
\end{abstract}

Materials and Methods: To assess adoption of human resource information system, this study applied the Unified Theory of Acceptance and Use of Technology (UTAUT). Data were collected from HR executives and HR professionals of different private and public organizations situated in Dhaka (capital of Bangladesh) and Chittagong (commercial capital of Bangladesh), Bangladesh. To analyze the data, researcher applied partial least square method based on structural equation modeling.

Results: The study found that the research factors performance expectancy, effort expectancy, social influence, facilitating condition as well as the extended factors of UTAUT model employee involvement and training support $(\mathrm{p}<0.05)$ had a weighty influence on HRIS adoption.

Conclusions: The findings of this study may become beneficial for the human resource department of various organizations (public, private and others) of developing countries like Bangladesh by adopting HRIS.

Keywords: human resource information systems, developing country, adoption, structural equation modeling, UTAUT, Bangladesh

\section{Introduction}

Over the last two decades, organizations have faced a good number of changes due to the globalization, rapid advancement of technology, the advent of a knowledge-based economy, competition and for other factors. As a result, human resource activities are also changing rapidly to keep with the organizational changes (Park, Gardner, \& Wright, 2004). Thus traditional HR system that previously practiced becomes absolute and insufficient with the passage of time (Beckers \& Bsat, 2002). HR with IT is the two-part and parcels that many organizations are learning to utilize as strategic weapons to stand against (Jenkins \& Lloyd, 1985). Again to cope with modern changes IT based HR can lead the human resource management in the new era (Lin, 1997). HRIS can be defined as a system that is used to obtain, store, manipulate, recuperate and deliver pertinent information about the organizational human resources (Thite, Kavanagh, \& Johnson, 2012).

Human resources of an organization are treated as strategic assets to achieve its sustainable competitive advantages over rivals. In human resources (HR) processes and practices, Information Technology (IT) has had a substantial effect (Stone, Deadrick, Lukaszewski, \& Johnson, 2015). Previously, first responses and access to information are the ultimate objectives of the implementation of HRIS (Ngai \& Wat, 2006). So, information sensitive organization intended to apply it more than others. But the application of HRIS becomes so vast and popular that now irrespective size, age, ownership status, and geographical location all organizations are trying to adapt HRIS to utilize its benefits. Appropriate HR reports and HR related data are essential to take the right decision related to management functions (Tripathi, 2011). HR data maintenance is bestowing organization to 
adopt Human Resource Information Systems.

From the early of 1945, organizations realized the significance of human resources. Although no mentionable changes observed till 1960, that pave the way for an explosion in 1960 in the field of HRIS (Kavanagh, Gueutal, \& Tannenbaum, 1990; Lederer, 1984). HRIS is now not only limited in administrative purposes but also significant for business and strategic purposes (Broderick \& Boudreau, 1992; Kossek, Young, Gash, \& Nichol, 1994; Kovach, Hughes, Fagan, \& Maggitti, 2002). In the global age, organizations and the working environments of organizations have become incrementally intricate. Managers of such kind of organizations are facing difficulties to cope with the workforces that spread across from various region even countries, cultures, and also political systems. In this situations, manual HR management systems are entirely insufficient (Beckers $\&$ Bsat, 2002).

Benefits also drew attention to the organizations of Asia. Bangladesh is not lagging behind to utilize the benefits of HRIS. Organizations of Bangladesh are trying to adapt HRIS practices in their organization to derive benefits. The government of Bangladesh also shows their concern in information system. Emphasis on ICT to confirm transparency and good governance in public sector was one of the important agenda in the last $7^{\text {th }}$ five-year plan $^{1}$ of Bangladesh. Organizations of Bangladesh have started to apply the information technology in various operations and sectors from the last decades with the apparition of globalization and digitalization. Only the large-scale corporate organizations are using HRIS for last five years and still limited due to their financial strength. Financial support is the first obstacle to implement IT (Ngai \& Wat, 2006). The purposes of using HRIS in both manufacturing and service-based organizations in Bangladesh are almost same (Bhuiyan \& Rahman, 2014).

Successful implementation is must in getting the maximum output from HRIS, and the successes of HRIS implementation needs through planning and proper monitoring (Sandeep K. Krishnan \& Manjaci Singh, 2007). However, it's a challenging issue in IT/IS research to make the people understand, why they accept or reject information technology (Al-Adawi, Yousafzai, \& Pallister, 2005). Companies are very disconcerted about the automated process, and its translation in HRIS leads to increase the expenses and trouble in implementing the system but like the customized packages (S. K. Krishnan \& M. Singh, 2007). High installation cost and maintaining are heavier challenges in the successful execution of HRIS (Beckers \& Bsat, 2002). Organizational culture shows up collective beliefs as well as values of the people employed (Schneider, Ehrhart, \& Macey, 2013). People's perceptions of technological changes should not underestimate. A favorable attitude towards innovations and ideas is significant to the seamless implementation of a new system (West \& Berman, 2001).

Substantial numbers of research work have been done in last two decades on HRIS in developed countries. However, very limited literature have found in developing countries under South Asian region. Some researchers have focused more on usages, for example, research of (Ball, 2001; Bamel, Bamel, Sahay, \& Thite, 2014; Hussain, Wallace, \& Cornelius, 2007; Kassim, Ramayah, \& Kurnia, 2012; Maier, Laumer, Eckhardt, \& Weitzel, 2013), etc. Some authors concentrate on the conditions for successful implementation of HRIS (Haines \& Petit, 1997; Winkler, König, \& Kleinmann, 2013). Again, HRIS implementation based on areas also addressed by other authors like (Ngai \& Wat, 2006; Razali \& Vrontis, 2010; Tansley \& Newell, 2007; Teo, Lim, \& Fedric, 2007).

Authors agreed upon that there is a paucity of research on HRIS in developing countries and the factors that are involved in HRIS adoption. Studies using adoption perspective attempt to evaluate the features of an organization that makes it receptive to change for technologies or innovations. This study attempts to use the Unified theory of acceptance and use of technology (UTAUT) model to investigate the influencing factors associated with HRIS adoption and to identify to what extent those factors affect the HRIS adoption in an organization.

\section{Research Model and Hypotheses Development}

This research is grounded in an extended UTAUT model to determine and interpret the impacts of factors that are influencing the adoption of HRIS. Venkatesh, Morris, Davis, and Davis (2003), scrutinized eight prominent models and incorporated the components of these different models into a single model. The model is more relevant in predicting the outcomes than any other models due to the logical proposition of existing theoretical models and higher comprehensiveness. The scrutinized models were Theory of Reasoned Action (TRA), Theory of Planned Behavior (TPB), Technology Acceptance Model (TAM), Motivational Model (MM), combined TAM and TPB, Model of PC Utilization (MPTU), Social Cognitive Theory (SCT) and Innovation Diffusion Theory

${ }^{1} 7^{\text {th }}$ Five year plan covers financial year 2015 to financial year 2020 
(IDT). The motive of the UTAUT model is to gain the unified view of user acceptance (Venkatesh et al., 2003) and this model can explain $70 \%$ of the variance in usage intention as well as can explain $50 \%$ of actual use (Raaij \& Schepers, 2008; Venkatesh et al., 2003).

UTAUT model is consists of four key constructs (i. performance expectancy, ii. effort expectancy, iii. social influence and iv. facilitating conditions) that act as the determinants of behavioral intentions and use behavior. In this study, the model is extended with employee involvement and training support. The HRIS itself is an emerging issue, particularly in Bangladesh context. Among other issues, employee involvement has been identified as a primary concern which can influence the adoption and use of HRIS (Green, 2012; Schraeder, Swamidass, \& Morrison, 2006). Training on the system to employees also necessary to be satisfied with the system and its usage to a greater extent (Cheney, Mann, \& Amoroso, 1986). Extended UTAUT model of the study given:

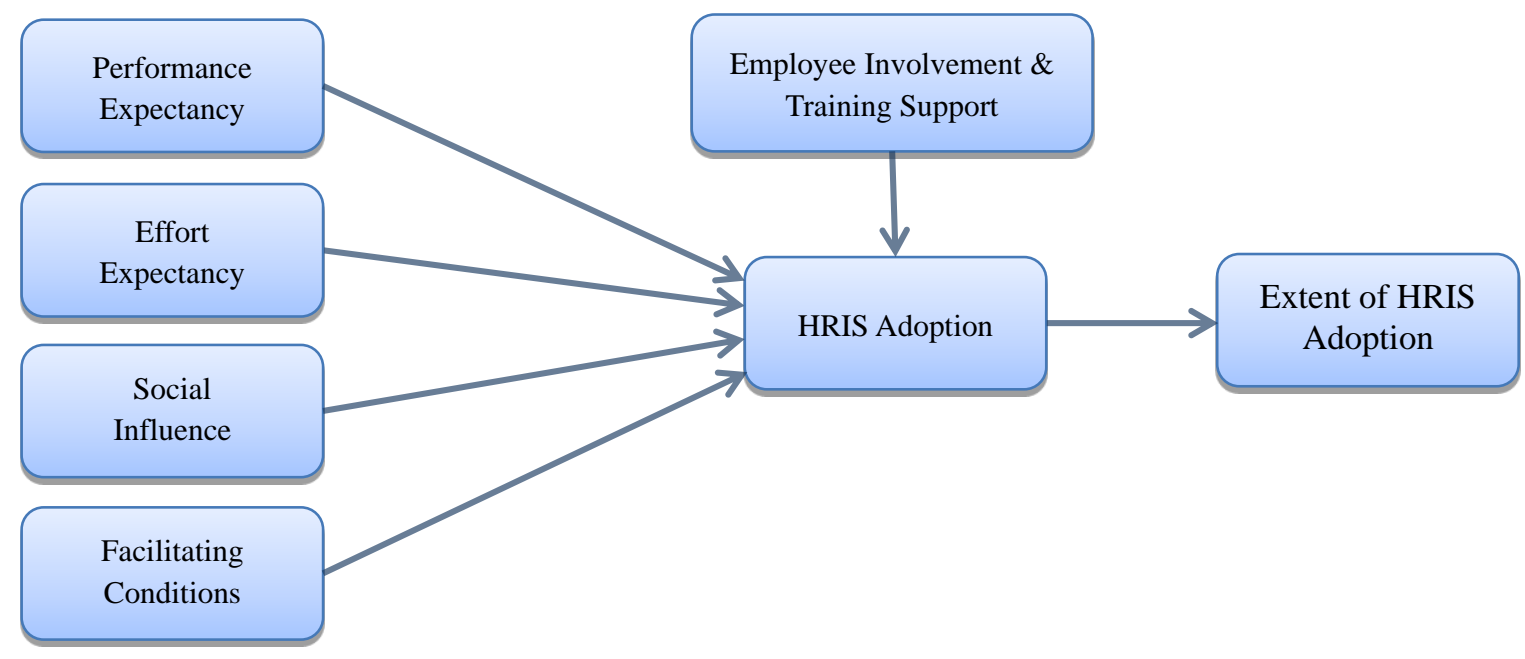

Figure 1. Research Model (Extended UTAUT model of the study)

\subsection{Performance Expectancy}

Performance expectancy of UTAUT model has been found as one of the most significant determinants to explain behavioral intention. It is defined as "the degree to which an individual believes that using the system will help him or her to attain gains in job performance" (Venkatesh et al., 2003, p. 447). The construct performance expectancy is derived from perceived usefulness (TAM/TAM2), extrinsic motivates (MM), result expectations (SCT), relative advantage (IDT), and job-fit (MPCU). The construct performance expectancy has the explanatory power regarding the intention to use technology as well HRIS adoption (Bandyopadhyay \& Fraccastoro, 2007). To delve the impact of the performance expectancy relevant hypothesis is:

Hypothesis 1: Performance expectancy will have a positive impact on HRIS adoption.

\subsection{Effort Expectancy}

The construct effort expectancy is defined as "the degree of ease associated with the use of the system" (Venkatesh et al., 2003, p. 450). It is formulated from three different constructs: perceived ease of use (TAM/TAM2), ease of use (IDT), and complexity (MPCU). Effort expectancy of UTAUT model is an important predictor of the purpose to use technology. It is predicted from the features of the technology, such as social presence, proximity, and concurrency along with individual as well as group characteristics, such as technology experience, computer self-efficacy, and familiarity with others (Brown, Dennis, \& Venkatesh, 2010). According to Aggelidis and Chatzoglou (2009), effort expectancy is an important determinant of users' intention to use IT. Based on the above arguments, the following hypothesis is thus postulated:

\section{Hypothesis 2: Effort expectancy will have positive impact on HRIS adoption.}

\subsection{Social Influence}

The construct social influence is defined as "the degree to which an individual perceives that important others believe he or she should use the new system" (Venkatesh et al., 2003, p. 451). It is derived from three others constructs: subjective norm (TRA, TAM2, TPB/DTPB and C-TAM-TPB), image (IDT) and social factors in MPCU. The intention of people to use new technology usually influenced by the thoughts and perceptions of his/her immediate environment. For what, this construct is more significant when the users are less involve with 
the technology (Venkatesh \& Davis, 2000; Venkatesh et al., 2003). Lu, Yao, and Yu (2005), indicated that this construct has a significant influence on behavioral intention at the early stage of technology adoption. From above explanation the following hypothesis can be drawn:

Hypothesis 3: Social influence will have positive impact on HRIS adoption.

\subsection{Facilitating Conditions}

Facilitating conditions is another antecedent of behavioral intention. Venkatesh et al. (2003, p. 453), defined facilitating conditions as "the degree to which an individual believes that an organizational and technical infrastructure exists to support the use of the system." It is driven from perceived behavioral control (TPB, C-TAM-TPB), facilitating conditions (MPCU), and compatibility (IDT). Venkatesh et al. (2003), noted that facilitating conditions would be measured directly with actual usage rather than behavioral intention, as it has a direct effect on the usage.

Yia, Jackson, Park, and Probst (2006), also indicated facilitating conditions as a direct construct of use technology. When trying with something new, people usually seek for assistance, especially when it comes to technology innovation. If the facilitating conditions are not sufficient, they may act as an inhibitor (Venkatesh, James Y. L. Thong, Frank K. Y. Chan, Paul Jen-Hwa Hu, \& Brown, 2011). In this study, facilitating conditions will represent the supports that employees expect in an organization to adopt HRIS. Accordingly, the following hypothesis is posited:

\section{Hypothesis 4: Facilitating conditions will have positive impact on HRIS adoption.}

\subsection{HRIS Adoption}

Pickett et al. (2012), described behavioral intention as "functions of both attitudes and subjective norms about the target behavior, predicting actual behavior". UTAUT argued and proved that behavior intention has a direct positive influence on technology adoption (Venkatesh, Thong, \& Xu, 2012; Venkatesh \& Zhang, 2010). Thong (1999), has talked about the extent of adoption among small firms but the operationalization of extent has been regarding number of system and software applications adopted across the organization. Similarly, the definition of extent of HRIS use is missing in most current ones (Kassim et al., 2012), where the study considers HRIS as an innovation and intend to observe the impact of HRIS on the extent of its use. Jasperson and Zmud. (2005), defined post-adoptive behavior as an amalgamation of feature adoption decisions, feature use behavior, and feature extension behavior made by an individual after an IT application has been fixed and successfully exploited. The researchers have drawn various prominent research models on technology acceptance and use. These models supported the relationship between the HRIS adoption and extent of HRIS adoption. Thus, we proposed the following hypothesis.

\section{Hypothesis 5: HRIS adoption and its impact have a positive influence on extent of HRIS adoption.}

\subsection{Employee Involvement \& Training Support}

Employee involvement in information systems development will ensure both system usage and employees' satisfaction with the system (Baroudi, Olson, \& Ives, 1986). Attitude to new ideas or innovations is significant to the execution of the new system. Information system execution might be restrained due to the lower trust and communication groups as well as staffs involvement (Kimberley \& Hartel, 2008). Project performance is significantly related to the known certainty and frequency of user involvement (Gales \& Mansour-Cole, 1995). If the employees were involved from the decisions related to technological changes would respond more positively in the adoption that particular technology than the employees with a low level of involvement (Schraeder et al., 2006). Users' training is essential in the adoption of HRIS. In most cases, HRIS features are not entirely utilized due to the lack of skill, lack of computer awareness or the difficulty in using the systems. Employees who have received more training on HRIS are awaited to be more pleased with the system and appliance it in greater extent (Cheney et al., 1986). The following hypothesis is thus postulated:

Hypothesis 6: Employee Involvement and Training support will have positive impact on individual behavior of using HRIS.

\section{Research Methodology}

The conceptual model of the study and hypotheses were presented in the previous part of the study. This part is planned to set out the research methodology to get answers of the research questions. Sekaran and Bougie (2010), defined research methodology as "structured set of guidelines or activities to assist in generating valid and reliable research results". The questionnaire of the study was developed and pretested with the faculty members of Comilla University, University of Dhaka and also with the help of HR executives and HR professionals of 
various organizations. Feedback was obtained on wording, sequence, structure and overall presentation of items.

HR executives and HR professionals of different private and public organizations situated in Dhaka (capital of Bangladesh) and Chittagong (commercial capital of Bangladesh), Bangladesh are considered as the target population for the study. Researcher desired to choose selective people within the population for a study or research project, purposive sampling technique is appropriate, and we used it to the study. Purposive sampling helps to find the people with particular characteristics who will be able to cooperate with the relevant research (Kothari, 2004). A matter of caution in this regard was that the findings from this type of sampling might not be lead to actual decision making.

Due to dynamic nature of the job, the employees of these companies were mostly familiar with IT products. HR professionals were the primary participants in this study. All potential respondents were emailed the soft version of the questionnaire, and three weeks after the first mailing, another round of mailing was carried to firms who have not responded. In total, 240 questionnaires were collected from 270. Ten (10) questionnaires were incomplete and excluded from the analysis. All variables were measured using Likert scale continuum ranging from 1 (stands for strongly disagree) to 5 (stands for strongly agree). Items of the survey were developed after an extensive survey of literature.

The structural equation modeling (SEM) was used to assess the relationship among the hypothesized concepts and validating the conceptual research model. According to, Oliver Götz, Kerstin Liehr-Gobbers, and Manfred Krafft (2010), SEM is a widely established model to validate theory with empirical data. Initially, Microsoft Excel was used to shape the raw data from questionnaire and imported to SmartPLS software, one of the mostly used statistical software for analyzing data (Hair Jr, Hult, Ringle, \& Sarstedt, 2016).

\section{Result}

\subsection{The Measurement Model}

The reliability and validity should be evaluated before testing the hypothesis (Bagozzi, Yi, \& Phillips, 1991). The reliability was assessed by using Cronbach's alpha and composite reliability. The composite reliability and Cronbach's alpha values of 0.70 or more are acceptable. According to Hair Jr et al. (2016), the composite reliability and Cronbach's alpha values below 0.60 indicate a lack of internal reliability. The composite reliability values and cronbach's alpha of all construct in Table 1 is more than 0.80 , which is higher than the recommended value. So, the constructs were deemed to have adequate reliability. The validity was weighed by considering convergent and discriminant validity. The convergent validity is taken to be satisfactory if the measurement constructs have at 0.50 as an average variance extracted (AVE) (Hair Jr, Anderson, Tatham, \& William, 1995). The measurement model table shows that AVE ranged from 0.698 to 0.829 are greater than the recommended value. Therefore, conditions for convergent validity were met. The discriminant validity was assessed by the square root of the AVE and cross loading matrix. The square root of the AVE of a construct must be larger than its correlation with other constructs for satisfactory discriminant validity (Henseler, Ringle, \& Sinkovics, 2009). The square roots of AVE, shown in the Table 2, were greater than their corresponding correlation, representing that our data had good discriminant validity.

Table 1. The measurement Model and Crossloading Matrix

\begin{tabular}{|c|c|c|c|}
\hline Construct & AVE & Composite Reliability & Cronbach's Alpha \\
\hline HRIS & 0.771 & 0.910 & 0.851 \\
\hline PE & 0.829 & 0.935 & 0.896 \\
\hline $\mathrm{EE}$ & 0.796 & 0.921 & 0.872 \\
\hline SI & 0.822 & 0.933 & 0.892 \\
\hline $\mathrm{FC}$ & 0.728 & 0.931 & 0.907 \\
\hline EITS & 0.698 & 0.873 & 0.837 \\
\hline
\end{tabular}

Table 2. Correlation Matrix and Square Root of the Average Variance Extracted

\begin{tabular}{llllllll}
\hline & HRIS & PE & EE & SI & FC & EITS & EHRIS \\
\hline HRIS & 0.878 & & & & & & \\
PE & 0.398 & 0.910 & & & & & \\
EE & 0.374 & 0.435 & 0.892 & & & & \\
SI & 0.245 & 0.435 & 0.426 & 0.802 & & & \\
FC & -0.357 & -0.487 & -0.337 & 0.211 & 0.907 & & \\
EITS & 0.504 & 0.577 & 0.454 & 0.320 & -0.581 & 0.853 & 0.835 \\
EHRIS & 0.287 & 0.477 & 0.340 & 0.455 & -0.348 & 0.499 & \\
\hline
\end{tabular}

4.2 Structural Model

To discover the path relationships within the constructs a structural research model was constructed and to test 
the hypothesis researcher used the bootstrap method. The study tests the association between endogenous and exogenous by path coefficient $(\beta)$ and $t$-statistics. The study observed that $\mathrm{PE}(\mathrm{t}=4.654, \beta=0.35), \mathrm{EE}(\mathrm{t}=5.304$, $\beta=0.39)$, SI $(\mathrm{t}=3.765, \beta=0.36), \mathrm{FC}(\mathrm{t}=2.870, \beta=0.27)$ and employee involvement and training support $(\mathrm{t}=4.735$, $\beta=0.36$ ) had a significant effect on HRIS adoption use m-health. Thus H1, H2, H3, H4 and H5 were supported. Finally, the result confirmed that HRIS adoption is positively associated with the extent of HRIS adoption $(\mathrm{t}=2.615, \beta=0.25$ ), supporting H6 (Table 3).

Table 3. Structural Model

\begin{tabular}{ccccc}
\hline Hypothesis & Path & $\beta$ & t-Statistics & Comment \\
\hline H1 & PE -> HRIS & 0.35 & 4.654 & Accepted \\
H2 & EE -> HRIS & 0.39 & 5.304 & Accepted \\
H3 & SI -> HRIS & 0.36 & 3.765 & Accepted \\
H4 & FC - > HRIS & 0.27 & 2.870 & Accepted \\
H5 & EITS - > HRIS & 0.36 & 4.735 & Accepted \\
H6 & HRIS -> EHRIS & 0.25 & 2.615 & Accepted \\
\hline
\end{tabular}

\section{Conclusion}

It is the first study that extended UTAUT model with employee involvement and training support in the context of HRIS adoption in developing countries. The findings of this study indicate that the extended UTAUT is a good predictive model of HRIS adoption. Regarding UTAUT-related variables, the results show that PE, EE, SI, FC and the factors of extended UTAUT model EITS had a significant influence on adoption of HRIS.

The developed model in this study can easily be applied for examining the adoption of HRIS in other developing countries. The findings of the study are essential for the development of policies and strategies to adopt HRIS in developing countries because it identified the key factors that influence to adopt HRIS. The decision makers of an organization should consider to think about the employee involvement and the training support before adopting any technologies like HRIS. The higher rate of HRIS adoption among the organizations' in developing countries has opened a prodigious opportunity to use information technology in HR department. The findings of this study can be used by policymakers of organizations and government for the public sector to increase the adoption of HRIS in developing countries. Finally, special attention should be given to users who do not have any experience with HRIS.

\section{References}

Aggelidis, V. P., \& Chatzoglou, P. D. (2009). Using a modified technology acceptance model in hospitals. International journal of medical informatics, 78(2), 115-126. https://doi.org/10.1016/j.ijmedinf.2008.06.006

Al-Adawi, Z., Yousafzai, S., \& Pallister, J. (2005). Conceptual model of Citizen Adoption of E-Government. in proceedings of the Second International Conference on Innovations in Information Technology (IIT'05), Dubai, United Arab, 26-28 September 2005, p 1-10.

Bagozzi, R. P., Yi, Y., \& Phillips, L. W. (1991). Assessing construct validity in organizational research. Administrative science quarterly, 421-458. https://doi.org/10.2307/2393203

Ball, K. S. (2001). The use of human resource information systems a survey, 30(6), 677-693.

Bamel, N., Bamel, U. K., Sahay, V., \& Thite, M. (2014). Usage, benefits and barriers of human resource information system in universities. The journal of information and knowledge management systems, 44(4), 519-536. https://doi.org/10.1108/VINE-04-2013-0024

Bandyopadhyay, K., \& Fraccastoro, K. A. (2007). The Effect of Culture on User Acceptance of Information Technology. Communications of the Association for Information Systems, 19, 522-543.

Baroudi, J. J., Olson, M. H., \& Ives, B. (1986). An Empirical Study of the Impact of User Involvement on System Usage and Information Satisfaction. Communications of the ACM, 29(3), 232-238. https://doi.org/10.1145/5666.5669

Beckers, A. M., \& Bsat, M. Z. (2002). A Dss Classification Model for Research in Human Resource Information Systems. Information Systems Management, 19(3), 1-10. https://doi.org/10.1201/1078/43201.19.3.20020601/37169.6

Bhuiyan, M. R. U., \& Rahman, M. R. (2014). Application of Human Resource Information System in the Firms of Bangladesh and Its Strategic Importance. World Review of Business Research, 4(3), 95-105.

Broderick, R., \& Boudreau, J. W. (1992). Human Resource Management, Information Technology, and the Competitive Edge. Academy of Management, 6(2), 7-17. https://doi.org/10.5465/AME.1992.4274391 
Brown, S. A., Dennis, A. R., \& Venkatesh, V. (2010). Predicting Collaboration Technology Use: Integrating Technology Adoption and Collaboration Research. Journal of management information systems, 27(2), 9-54. https://doi.org/10.2753/MIS0742-1222270201

Cheney, P. H., Mann, R. I., \& Amoroso, D. L. (1986). Organizational factors affecting the success of end-user computing. J. Manage. Inf. Syst., 3(1), 65-80. https://doi.org/10.1080/07421222.1986.11517755

Gales, L., \& Mansour-Cole, D. (1995). User involvement in innovation projects: Toward an information processing model. Journal of Engineering and Technology Management JET-M, 12, 77-109. https://doi.org/10.1016/0923-4748(95)00005-7

Green, F. (2012). Employee involvement, Technology and Evolution in Job Skills: A Task-Based Analysis. Sage Publications, Inc. is collaborating with JSTOR to digitize, preserve and extend access to ILR Review. ILR Review, 65(1), 36-67. https://doi.org/10.1177/001979391206500103

Haines, V. Y., \& Petit, A. (1997). CONDITIONS FOR SUCCESSFUL HUMAN RESOURCE INFORMATION SYSTEMS. Human resource management, 36(2), 261-275. https://doi.org/10.1002/(SICI)1099-050X(199722)36:2<261::AID-HRM7>3.0.CO;2-V

Hair Jr, J. F., Anderson, R. E., Tatham, R. L., \& William, C. (1995). Multivariate data analysis with readings. New Jersy: Prentice Hall.

Hair Jr, J. F., Hult, G. T. M., Ringle, C., \& Sarstedt, M. (2016). A primer on partial least squares structural equation modeling (PLS-SEM): Sage Publications.

Henseler, J., Ringle, C. M., \& Sinkovics, R. R. (2009). The use of partial least squares path modeling in international marketing New challenges to international marketing (pp. 277-319): Emerald Group Publishing Limited.

Hussain, Z., Wallace, J., \& Cornelius, N. E. (2007). The use and impact of human resource information systems on human resource management professionals. Information \& Management, 44(1), 74-89. https://doi.org/10.1016/j.im.2006.10.006

Jasperson, J., Carter, P. E., \& Zmud, R. W. (2005). A comprehensive conceptualization of post-adoptive behaviours associated with Information Technology enabled work systems. MIS quarterly, 29(3), 525-557. https://doi.org/10.2307/25148694

Jenkins, M. L., \& Lloyd, G. (1985). How corporate philosophy and strategy shape the use of HR information systems. Personnel, 62(5), 28-38.

Kassim, N. M., Ramayah, T., \& Kurnia, S. (2012). Antecedents and outcomes of human resource information system (HRIS) use. International Journal of Productivity and Management, 61(6), 603-623. https://doi.org/10.1108/17410401211249184

Kavanagh, M. L., Gueutal, H. G., \& Tannenbaum, S. I. (1990). Human resource information systems: Development and application: PWS-Kent Publishing Company.

Kimberley, N., \& Hartel, C. E. (2008). Employee-customer interface in a service crisis. Impact of senior management attributes and practices on customer evaluation. JOURNAL OF MANAGEMENT \& ORGANIZATION, 14(2), 207-218. https://doi.org/10.1017/S1833367200003400

Kossek, E. E., Young, W., Gash, D. C., \& Nichol, V. (1994). Waiting for Innovation in the Human Resources Department Godot Implements a Human Resource Information System. Human resource management, 33(1), 135-159. https://doi.org/10.1002/hrm.3930330108

Kothari, C. R. (2004). Research Methodology - Methods and Techniques. New Age International Publishers, New Delhi, India.

Kovach, K. A., Hughes, A. A., Fagan, P., \& Maggitti, P. G. (2002). Administrative and Strategic Advantages of HRIS. Employment Relations Today, 29(2), 43-48. https://doi.org/10.1002/ert.10039

Krishnan, S. K., \& Singh, M. (2007). Issues and Concerns in the Implementation and Maintenance of HRIS. Management and Labour Studies, 32(4), 522-540. https://doi.org/10.1177/0258042X0703200407

Lederer, A. L. (1984). Planning and developing a human resource information system. The logic of a step-by-step approach. The Personnel Administrator, 29(8), 27-39.

Lin, C. Y. Y. (1997). Human Resource Information Systems: Implementation in Taiwan. Research and Practice in Human Resource Management, 5(1), 57-72. 
Lu, J., Yao, J. E., \& Yu, C. S. (2005). Personal innovativeness, social influences and adoption of wireless Internet services via mobile technology. The Journal of Strategic Information Systems, 14(3), 245-268. https://doi.org/10.1016/j.jsis.2005.07.003

Maier, C., Laumer, S., Eckhardt, A., \& Weitzel, T. (2013). Analyzing the impact of HRIS implementations on HR personnel's job satisfaction and turnover intention. The Journal of Strategic Information Systems, 22(3), 193-207. https://doi.org/10.1016/j.jsis.2012.09.001

Ngai, E. W. T., \& Wat, F. K. T. (2006). Human resource information systems a review and empirical analysis. 35(3), 297-314. https://doi.org/10.1108/00483480610656702

Oliver, G., Kerstin, L. G., \& Manfred Krafft. (2010). Evaluation of structural equation models using the partial least squares (PLS) approach. In: Vinzi V, Chin WW, Henseler J, Wang H, eds. Handbook of partial least squares. Berlin Heidelberg: Springer, 691-711.

Park, H. J., Gardner, T. M., \& Wright, P. M. (2004). HR practices or HR capabilities: which matters? Insights from the Asia Pacific region. Asia Pacific Journal of Human Resources, 42(3), 260-273. https://doi.org/10.1177/1038411104045394

Pickett, L. L., Ginsburg, H. J., Mendez, R. V., Lim, D. E., Blankenship, K. R., Foster, L. E., ... Sheffield, S. B. (2012). Ajzen's theory of planned behavior as it relates to eating disorders and body satisfaction. North American Journal of Psychology 14(2), 339-354.

Raaij, E. M. V., \& Schepers, J. J. L. (2008). The acceptance and use of a virtual learning environment in China. Computers \& Education, 50(3), 838-852. https://doi.org/10.1016/j.compedu.2006.09.001

Razali, M. Z., \& Vrontis, D. (2010). The Reactions of Employees Toward the Implementation of Human Resources Information Systems (HRIS) as a Planned Change Program: A Case Study in Malaysia. Journal of Transnational Management, 15(3), 229-245. https://doi.org/10.1080/15475778.2010.504497

Schneider, B., Ehrhart, M. G., \& Macey, W. H. (2013). Organizational Climate and Culture. Annual Review of Psychology, 64(1), 361-388. https://doi.org/10.1146/annurev-psych-113011-143809

Schraeder, M., Swamidass, P. M., \& Morrison, R. (2006). Employee Involvement, Attitudes and Reactions to technology Changes. Journal of Leadership and Organizational Studies, 12(3), 85-100. https://doi.org/10.1177/107179190601200306

Sekaran, U., \& Bougie, R. (2010). Research Methods for Business: A Skill-Building Approach (5th Edition). Jhon Willey \& Sons Ltd.

Stone, D. L., Deadrick, D. L., Lukaszewski, K. M., \& Johnson, R. (2015). The influence of technology on the future of human resource management. Human Resource Management Review, 25(2), 216-231. https://doi.org/10.1016/j.hrmr.2015.01.002

Tansley, C., \& Newell, S. (2007). A Knowledge-based View of Agenda-formation in the Development of Human Resource Information Systems. Management Learning, 38(1), 95-119. https://doi.org/10.1177/1350507607073028

Teo, T. S. H., Lim, G. S., \& Fedric, S. A. (2007). The adoption and diffusion of human resources information systems in Singapore. Asia Pacific Journal of Human Resources, 45(1), 44-62. https://doi.org/10.1177/1038411107075402

Thite, M., Kavanagh, M. J., \& Johnson, R. D. (2012). Evolution of Human Resource Management and Human Resource Information Systems. Sage Publications, 2-35.

Thong, J. Y. (1999). An integrated model of information systems adoption in small businesses. Journal of management information systems, 15(4), 187-214. https://doi.org/10.1080/07421222.1999.11518227

Tripathi, K. P. (2011). A Study of Information Systems in Human Resource Management (HRM). International Journal of Computer Applications, 22(8), 9-11. https://doi.org/10.5120/2606-3635

Venkatesh, V., \& Davis, F. D. (2000). A Theoretical Extension of the Technology Acceptance Model: Four Longitudinal Field Studies. Management Science, 46(2), 186-204. https://doi.org/10.1287/mnsc.46.2.186.11926

Venkatesh, V., James, Y. L., Thong, F. K. Y., Chan, P. J. H., \& Brown, S. A. (2011). Extending the two-stage information systems continuance model: incorporating UTAUT predictors and the role of context. Information Systems Journal, 21(6), 527-555. https://doi.org/10.1111/j.1365-2575.2011.00373.x 
Venkatesh, V., Morris, M. G., Davis, G. B., \& Davis, F. D. (2003). User Acceptance of Information Technology: Toward a Unified View. MIS quarterly, 27(3), 425-478. https://doi.org/10.2307/30036540

Venkatesh, V., Thong, J. Y. L., \& Xu, X. (2012). Consumer acceptance and use of Information Technology: Extending the Unified Theory of Acceptance and Use Technology. MIS quarterly, 36(1), 157-178.

Venkatesh, V., \& Zhang, X. (2010). Unified Theory of Acceptance and Use of Technology: U.S. Vs. China. Journal of Global Information Technology Management, 13(1), 5-27. https://doi.org/10.1080/1097198X.2010.10856507

West, J. P., \& Berman, E. M. (2001). From Traditional to Virtual HR. Review of Public Personnel Administration, 21(1), 38-64. https://doi.org/10.1177/0734371X0102100104

Winkler, S., König, C. J., \& Kleinmann, M. (2013). What makes human resource information successful? Managers' perceptions of attributes for successful human resource information. The International Journal of Human Resource Management, 24(2), 227-242. https://doi.org/10.1080/09585192.2012.680068

Yia, M. Y., Jackson, J. D., Park, J. S., \& Probst, J. C. (2006). Understanding information technology acceptance by individual professionals: Toward an integrative view. Information \& Management, 43(3), 350-363. https://doi.org/10.1016/j.im.2005.08.006

\section{Copyrights}

Copyright for this article is retained by the author(s), with first publication rights granted to the journal.

This is an open-access article distributed under the terms and conditions of the Creative Commons Attribution license (http://creativecommons.org/licenses/by/4.0/). 